\title{
LUMBAR EPIDURAL ANAESTHESIA FOR OBSTETRICS AT THE TORONTO GENERAL HOSPITAL
}

IAIN M. MACKAY, M.D, F.A.C.A *

FOR SOME TIME the problem of maternal mortality and morbidity due to the aspiration of vomitus during general anaesthesia for obstetrics has been of concern to the medical profession. The aspiration of stomach contents causes up to 10 per cent of deaths attributable to anaesthesia and in a recent survey is blamed for almost 50 per cent of maternal deaths The danger of this catastrophe is obviously greater in obstetrical anaesthesia than in any other unselected group of patients.

Any patient whose labour has begun within three hours after eating or who has taken food after labour has begun must be considered to have a full stomach. If labour is at all prolonged ileus and gastric dilatation are likely to be present to some degree.

Some nurses insist on giving, or are ordered to give, fluids to a patient in prolonged labour in an ill-advised attempt to mantan the patient's fluid balance. The well-known fact that the flud remains in the stomach and cannot balance anything except the weight of the gravid uterus does not changé hospital routines.

Because of the dangers of the full stomach some of us feel that a regional technique should be used whenever possible for obstetrical anaesthesia

Epidural anaesthesia 1s, of course, nothing new. As caudal anaesthesia, it was in vogue in Toronto for a time in the early forties, but its popularity suddenly waned and it gained an undeservedly bad reputation from which it has not recovered in this centre, although it is still used here from time to time and is extensively used elsewhere.

Lumbar epidural block was first used for obstetrics in the Toronto General Hospital in 1949 for four Caesarian sections In 1954 it was used for three vaginal deliveries and attempted for one Caesarian section In 1955 it was used in fortysix obstetrical cases It has rapidly become more popular and in 1956 in the Private Pavilion, the Burnside Hospital, and the Wellesley Division it was used for 645 patients.

The charts of all of these patients have been reviewed for data on the efficiency of the block, the technıque used, and complications both during and after delivery, attributable to anaesthesia. Most of the information has been obtained from the anaesthesia record, the nurses' labour record, and the occasional note by either obstetrician or anaesthetist Information regarding post-partum complications has come mainly from the ward nurses, the obstetrician, or our own suspicions

- Read at a meeting of the Section of Anaesthesia, Academy of Medicine of Toronto. November 19, 1956

"Department of Anaesthesia, University of Toronto and Toronto General Hospital 


\section{Technique}

Anaesthetists defter as much in their preference for certain methods and materials as do patients in their requirements However, certain principles are observed by all

Aseptic technique is of primary importance. It is also of great importance to protect the instruments and drugs used for epidural analgesia from contamination by antıseptics used for skın preparation and sterilızation.

In our hands the most commonly used technique is as follows. after skm preparation with a solution of Benzalkonium chloride, a skin wheal is made in the lumbar region-preferably at the L3-L4 level or even lower. Through this skin wheal a $31 / 2$ inch 16-gauge needle is inșerted into the epidural space. After positive identification of this space the drug of choice is injected

The most commonly used method for identifying the epidural space is the pressure injection of aur in a small syringe attached to the slowly advancing needle Some anaesthetists prefer to have the syringe filled with saline or the local anaesthetic drug In a consıderable number of cases in this series a Macintosh Epidural needle was used. This needle possesses a spring-loaded stilette which acts as an indicator and pushes the dura mater in front of it.

The use of a large-bore needle in preference to the 21 - or 22 -gauge needle so otten advocated minimizes the danger of inadvertent puncture of the dura mater and at the sâme time ensures that any such puncture cannot fail to be recognized at once

The drug most frequently used in this series has been Xylocaine brand of lidocaine The amount used was from 15 to $25 \mathrm{ml}$. of a solution the strength of which varied from 13 per cent to 2 per cent Sometimes a solution was used contanning epinephrine in a concentration of 1 in 200,000 or 1 in 100,000. One anaesthetist, almost consistently, uses Cyclame brand of hexylcaine, 1 per cent, without epmephrine These variations appear to have little influence on the effectiveness of the epidural block althongh they may alter height of analgesia and its duration to some small extent.

Sometimes a polyethylene catheter has been inserted in the epidural space to allow the block to be repeated if necessary In these cases a Tuohy needle has been used

Epidural block is most usually performed withm thirty minutes of the expected tme of delivery. If the patient is primiparous, block is performed after the cervix has dilated fully and the foetal head has come well down into the pelvis. If the patient is multiparous, blook may be performed before full dilatation of the cervix is accomplished As the analgesia usually lasts for about ninety minutes and mistakes in timing can be made, the block may have to be repeated No ill effects have resulted from doing this.

The only major technical difficulty cxperienced in this series of cases has been due to the unco-operativeness of many patients consequent on their reaction to sedation. Although this may very infrequently contraindicate epidural block, this type of analgesia has been quite satisfactory in most cases. 


\section{Summary of Cases}

The figures quoted in this series take into account only lumbar epıdural block. Caudal block is not considered.

Lumbar epidural block was used for 699 cases of which 623 were vaginal deliveries, 76 were Caesarian sections. With most of the Caesarıan sections the patients were given some general anaesthesia as well, chiefly to keep them quiet and only rarely because of inadequate epidural analgesia

For 36 patients only was it necessaly to use true general anaesthesia such as cyclopropane or trichlorethylene, with or without a relaxing agent at the time of delivery. For eleven of these the blocks had been performed 1/2 to 2 hours before delivery and had almost completely worn oft

Thirty-five patients were given nitrous oxide, 50-75 percent, with oxygen, to relieve the discomfort of traction on forceps or merely to allay the patient's apprehension

Three epidural blocks were performed too late for usefulness, that is, the patient delivered herself.

It has been our impiession, although the charts do not give this information, that usually labour was netther stopped nor delayed by epıdural block. In some cases uterine contractions were stopped for a time but this is unusual. The patient, of course, was no longer aware of contractions, but if told to "push" she was usually able to reinforce the uterme contraction with her own abdominal muscles.

Analgesia has in few patients been inadequate or absent over the perineum but this was unusual and in most the desired degree of anaesthesia has extended up to the seventh or eighth thoracic segment

\section{Complications during Labour}

The anaesthesia records of the charts of six patients contained comments on a rise in blood pressure and the occurrence of vomiting and/or headache almost immediately following the intravenous injection of ergometrine It is probable that the actual meidence of this phenomenon was much greater in this series as it has been independently commented on by the nurses from time to tume.

A considerable drop in blood pressure has been noted for four patients One of these apparently was inadvertently given a high spinal block, necessitating the use of vaso-pressors and control of respirations for forty minutes.

One patient had tungling and weakness of one hand for about fifteen minutes following epidural block, indicating that the drug had tracked higher than usual in the extradural space. This patient had a moderate drop in blood pressure quickly controlled by intravenous methedrine.

One patient, who had received no sedation durng labour, began to shiver a few minutes after epidural injection and seemed unable to remain quiet. She was an extremely nervous woman and remarked that she had done this sort of thing on previous occasions She was adequately sedated with $125 \mathrm{mgm}$ of thiopentone sodium

The fourth patient exhibited a marked, sudden drop in blood pressure. Immediately prior to this, the foetal heart sounds had appeared normal. Following the 
diop in pressure the foetal heart sounds were slower and weaker. Although delivered almost immediately the infant was stillborn and could not be resuscitated While other factors may have been involved, the period of hypotension cannot be ruled out as the cause of foetal death.

Although it is not recorded in the charts, it is the clinical impression of a number of anaesthetists at the Toronto General Hospital that the phenomenon of shivering and restlessness occurred farrly often in the unsedated patient, that analgesia was not as effective in the unsedated, and that, quite possibly, one of the drugs used, Xylocaine, tended to make the patient drowsy

\section{Post-Partum Complications}

These have been infrequent and minor

One patient developed convulsions some two or three hours following delivery and some time after the epidural block had worn off completely. It was considered a possibility that the convulsion might have been due to ergometrine, two doses of which had been given intravenously. One patient developed eclampsia in the post-partum period

It is improbable that either of these complications is attributable to epidural block

The most troublesome and most frequently noted post-partum complication has been "low pressure headache." This syndrome is in all probability due to inadvertent puncture of the dura mater during insertion of a needle into the epidural space The syndrome is one of headache developing as soon as the patient gets up from the recumbent position, accompanied by pain in the neck and sometimes the shoulders. The neck is stiff and neck flexion is very painful. Lying down relieves the headache promptly

Only nıne cases have been noted on the charts in this series of 699 cases. Three other patients had low pressure headache, although no complaint was made. The discovery was made only after the headache syndrome had disappeared. Many patients, of course, will not complain unless the suggestion is made to them. For three patients, although the dura is known to have been punctured, there is no record of headache having developed.

Although this type of headache is most unpleasant it is obviously much less a problem than it is with spinal analgesia, in which it is reported as affecting 10-25 per cent of the patients in some centres However, the headache is generally more severe than the usual "post spinal headache." This may be due to the fact that the patient about to have an epidural block has often been encouraged by her obstetrician to expect complete freedom from headache and an ideal delivery and post-partum period Another factor is the large needle most frequently used for epidural block and the consequently larger puncture wound in the dura

The treatment of this complication has been to keep the patient flat in bed for at least forty-eight hours, giving the dura mater time to seal off. At the end of this time the cervical component of the headache is usually gone although the cranial component may persist for another two or three days

The injection of normal saline into the epidural space was performed once in this series to relieve the headache The headache returned in about thirty-six 
hours but was less severe. Intravenous fluids have been administered to some patients for this condition but with no clearly beneficial effect.

One patient was subjected by her obstetrician to a rather panicky investigation of the cerebrospinal system The spinal puncture showed no evidence whatever of meningeal irritation or infection and the cerebrospinal fluid pressure is reported to have been below normal both before and after puncture.

The three patients with proven dural puncture, who remained free of headache, probably did so because they were instructed by their anaesthetist to lie flat for the first forty-eight hours of the post-partum period.

A few patients have developed a hypertensive headache following delivery, which has been attributed, wrongly, of course, to dural puncture. These patients, however, responded to fluids per os or intravenously and to acetylsalicylic acid or other mild sedative. They showed relief of symptoms when sitting or standing and accentuation of headache when they lay flat

\section{SUMMARY}

A review of 699 obstetrical cases on whom lumbar epidural block was performed shows that this technique has become quite popular in the Toronto General Hospital. The method used, in the hands of the experienced anaesthetist, produces satisfactory analgesia in the great majority of cases and seldom requires reinforcement by general anaesthetic techniques

The complications of the method are few in number and minor in character

\section{RÉSUMÉ}

Surtout à cause des risques que comporte l'anesthésie généiale chez les malades non à jeun, l'anesthésie épıdurale en obstétrique est devenue très populaire depuìs deux ans à l'hôpital Toronto General et cela aussi bien au cours de la Césarienne qu'au cours de l'accouchement par les voles naturelles.

Nous avons revisé une série de 699 cas et avons étudié la technique, l'efficacité, les complications au temps de l'accouchement et au cours des suites opératoires

Nous insistons sur la nécessité d'une technique ngoureusement aseptique et sur l'absence de toute contamination chimique

Nous donnons une description de la méthode employée le plus souvent pour identifier l'espace épidural ains1 que celle des appareils et nous mentionnons les médicaments employés le plus souvent au cours de la série

Il n'a été que rarement nécessaire de compléter le blocage nerveux par l'anesthésıe générale et quand il y eut lieu de le fairre nous n'avons employé que du protoxide à 50-75 pour cent avec oxygène

Avec ce genre d'anesthésie, les complications sont peu nombreuses et, dans les mains d'un anesthésiste d'expérience, ne sont pas sérieuses. La céphalée, des nausées et des vomissements ont souvent suivi l'administration intraveineuse d'Ergométrine Dans de nombreux cas, à la suite d'une sédation insuffisante, on a observé de l'appréhension et des frissons

Chez quatre malades, nous avons noté une hypotension prononcée. Chez une de ces malades, l'hypotension pourrait être responsable de la naissance d'un enfant mort-né quoique d'autres facteurs pourraient également être évoqués. 
Chez douze malades, nous avons observé de la céphalée par hypotension dans le liquide céphalo-rachidien à cause de l'entrée par inadvertance dans le sac dural. Cette complication a été la plus ennuyeuse mais, dans la plupart des cas, elle a cédé en gardant la malade horizontale dans son lit durant 48 heures. Toutefois, cette éventualité a été moins fi:équente qu'au cours de l'anesthésie rachidienne et elle a été quelques fois confondue au cours des suites de couche immédiates avec des céphalées de tension qui sont dues en partie à la déshydratation et qui sont facilement traitées.

Au cours de cette série, nous n'avons pas observé de séquelles permanentes attribuables à l'anesthésie épidurale et nous estimons que le bloc épidural lombarre est une méthode d'anesthésie satisfassante en obstétrique 